Revista Destaques Acadêmicos, Lajeado, v. 10, n. 3, 2018. ISSN 2176-3070

DOI: http://dx.doi.org/10.22410/issn.2176-3070.v10i3a2018.1948

http://www.univates.br/revistas

\title{
AVALIAÇÃO FÍSICO-QUÍMICA DO FRUTO ARAÇÁ- BOI (Eugenia stipitata MacVaugh) CULTIVADO NA MESORREGIÃO DO SUDOESTE MATO-GROSSENSE
}

\author{
Rosângela da Silva Souza ${ }^{1}$, Sumária Sousa e Silva², Raquel Aparecida Loss ${ }^{3}$, \\ Rosana da Silva Souza ${ }^{4}$, Sumaya Ferreira Guedes ${ }^{5}$
}

Resumo: O Brasil apresenta uma enorme diversidade de frutos nativos comestíveis, porém nem sempre são amplamente conhecidos e consumidos. Dentre esses frutos encontra-se o araçá-boi (Eugenia stipitata MacVaugh), com grande potencial na indústria alimentícia, devido a sua composição nutricional. A fim de favorecer o consumo desse fruto em diferentes regiões do país, bem como um melhor aproveitamento da produção, objetivou-se com o presente estudo avaliar os parâmetros físico-químicos (umidade, acidez em ácido cítrico, $\mathrm{pH}$, cinzas, sólidos solúveis totais e lipídios) do fruto araçá-boi proveniente de três cidades da mesorregião do sudoeste do estado de Mato Grosso (Rio Branco, São José dos Quatro Marcos e Salto do Céu). As análises foram realizadas com o fruto em suas partes isoladas (casca, polpa e semente). Os resultados globais mostraram que o fruto apresentou baixo $\mathrm{pH}$ e elevada acidez e um alto teor de umidade. Sendo que a casca e polpa apresentaram características físico-químicas semelhantes entre si e

1 Graduada em Engenharia de Alimentos (Universidade do Estado de Mato Grosso- UNEMAT).

2 Graduada em Licenciatura Plena em Química (Universidade Estadual do Piauí-UESPI). Mestre em Ciências (Universidade de São Paulo-USP). Doutora em Ciências (Universidade de São Paulo-USP). Bolsista de Pós-doutorado (DCR/CNPq/FAPEMAT), Universidade do Estado de Mato Grosso (UNEMAT), Campus de Barra do Bugres- MT.

3 Graduada em Engenharia de Alimentos (Universidade de Passo Fundo- UPF). Mestre em Engenharia de Alimentos (Universidade Federal de Santa Catarina, UFSC). Doutora em Engenharia de Alimentos (Universidade Federal de Santa Catarina, UFSC). Professora da Universidade do Estado de Mato Grosso (UNEMAT), Campus de Barra do Bugres- MT.

4 Graduanda em Engenharia de Produção Agroindustrial (Universidade do Estado de Mato Grosso- UNEMAT).

5 Graduada em Licenciatura Plena em Química (Universidade Federal de Mato Grosso- UFMT). Mestre em Tecnologia e Segurança Alimentar (Universidade Nova de Lisboa- Faculdade de Ciências e Tecnologia (UNL-FCT- Portugal). Doutora em Química (Universidade Estadual de Campinas- UNICAMP). Professora da Universidade do Estado de Mato Grosso (UNEMAT), Campus de Barra do Bugres- MT. 
diferentes da semente. Além disso, o período e região da coleta influenciaram em todas as características físico-químicas do fruto.

Palavras-chave: Eugenia stipitata. Fruto exótico. Fruto não-climatérico.

\section{INTRODUÇÃO}

A floresta amazônica abriga aproximadamente $50 \%$ da biodiversidade do planeta e é um território conhecido pela sua grande diversidade global. Essa biodiversidade encontrada nesse bioma proporciona a existência de muitas variedades de frutos exóticos com benefícios a saúde, sabor agradável, que podem servir como matéria-prima em muitos alimentos como geleias, sorvetes, ou simplesmente ser consumido in natura. Entretanto, a maioria dos frutos são pouco conhecidos, devido à dificuldade de manejo para algumas plantas, falta de conhecimento sobre características físico-química e microbiológica, além do clima de algumas regiões não favorecerem o cultivo (NERI-NUMA et al., 2013; VANIN, 2015).

Dentre as frutas com grande potencial para comercialização, porém pouco conhecida na maior parte do Brasil, destaca-se o araçá-boi (Eugenia stipitata). $\mathrm{O}$ araçá-boi pertence à família Myrtaceae, gênero Eugenia stipitata McVaugh. Ele é originário da Amazônia Ocidental Brasileira, mas também pode ser encontrado em diversos outros países como: Peru, Bolívia, Equador e Colômbia (FERREIRA; RIBEIRO, 2006; SACRAMENTO et al., 2008). Apresenta alto valor nutricional, e compostos bioativos, que diminuem o processo inflamatório no organismo humano. Além de conter alto teor de compostos fenólicos, carboidratos, proteínas e vitaminas C e E (VANIN, 2015). Entretanto, a literatura não destaca um estudo completo sobre este fruto com análise físicoquímica das suas partes isoladas: casca, polpa e semente, além de apresentar poucas informações sobre as potencialidades tecnológicas.

No Brasil, a maior produção desse fruto ocorre na Amazônia Ocidental, uma região caracterizada pelo clima quente e úmido proporcionado pela evaporação e as altas temperaturas, com médias entre $24,5^{\circ} \mathrm{C}$ e $32^{\circ} \mathrm{C}$, elevados índices de chuva, e umidade relativa de aproximadamente $90 \%$. Entretanto é inviável o transporte in natura devido à alta perecibilidade, por se tratar de um fruto sensível e delicado quando maduro e, por ser não-climatérico, não pode ser coletado ainda verde (SOARES, 2009; VANIN, 2015).

O araçazeiro (Figura 1) é uma árvore de pequeno porte, e pode chegar até 3 metros e meio de altura. Adapta-se melhor com exposição solar constante, entretanto, em locais com sombra também apresenta um resultado satisfatório. Existe uma enorme diversidade de araçás, sendo os mais comuns o araçávermelho, araçá-amarelo, araçá-pêra, araçá-pitanga e o araçá-boi. O araçá-boi floresce e frutifica várias vezes ao ano, e o tempo necessário para floração até o estádio maduro demora aproximadamente dois meses. Isso é um fator atrativo 
para indústria, devido a disponibilidade de matéria-prima a partir do segundo ano de idade (FALCÃO et al., 2000).

Figura 1- O araçazeiro, uma árvore de pequeno porte.

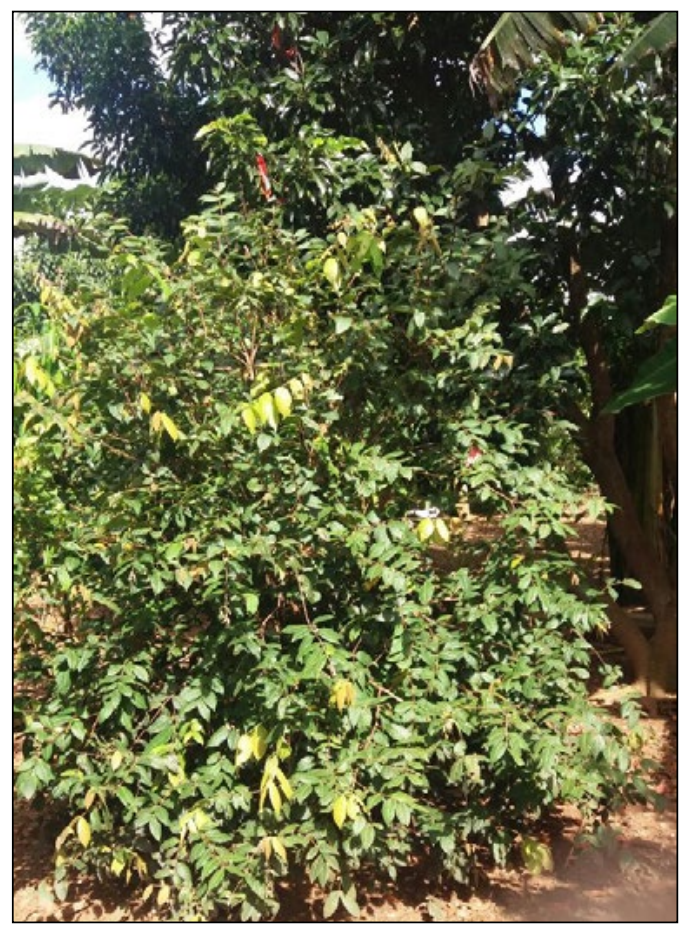

Fonte: Próprio autor, 2018.

O fruto do araçazeiro apresenta uma baga globosa, ou seja, a sua polpa está diretamente interligada com as sementes, de modo que seu epicarpo seja delgado (Figura 2A). Seu peso varia de 30 a $80 \mathrm{~g}$, apresentando um formato arredondado, com uma aparência levemente achatada. O diâmetro longitudinal pode variar de 4 a 9,7 cm e diâmetro transversal de 4,3 a 9,9 cm (SACRAMENTO et al., 2008). Possui uma casca fina com coloração amarela e sua polpa apresenta um tom mais claro quando está no ponto de colheita (VANIN, 2015). Cada fruto apresenta em média de 3 a 22 sementes com 0,5 a 1,0 cm de comprimento. Sensorialmente a polpa (Figura 2B) é suculenta, com sabor agridoce, e devido sua acidez normalmente é consumida na forma de sucos, doces, sorvetes, entre outros (GENTIL; FERREIRA, 2000). Utiliza-se também o fruto em mistura com outras frutas para a produção de doces como de mamão e banana (SOARES, 2009).

Quando esses frutos estão maduros, eles são sensíveis e delicados, amassando com facilidade, de modo que seu manuseio se torna difícil para serem transportados a longas distâncias. Neste caso é recomendado que 
seja realizado o beneficiamento de sua polpa para posteriormente serem transportadas e seguir o seu processamento para obtenção de produtos para a comercialização (SOARES, 2009).

Figura 2- (A) Frutos do araçá-boi em diferentes estádios de maturação. (B) Polpa do fruto maduro.

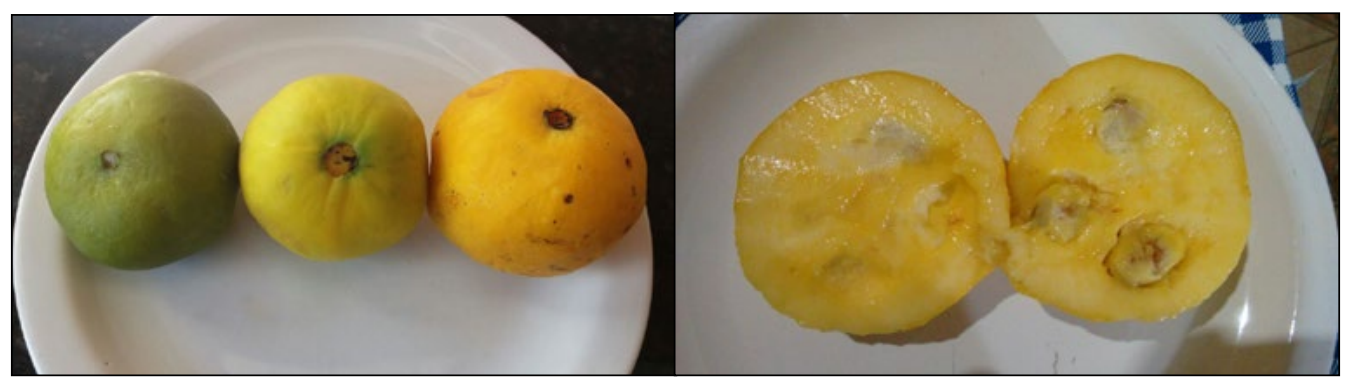

Fonte: Próprio autor, 2018.

A polpa do araçá-boi apresenta sabor e aroma peculiares, sendo rica em teor de água, proteína, carboidratos, fibras, sais minerais e em sua casca possui tanino. Estes compostos são de extrema importância para a saúde e bom funcionamento do organismo, pois apresentam em sua composição um valor considerável de vitaminas, sobretudo vitamina $C$ que ajuda na manutenção imunológica do organismo (SOARES, 2009). Entretanto, no processamento das frutas pode ocorrer a degradação do ácido ascórbico, principalmente se estiver em altas temperaturas, através dos íons metálicos e enzimas que se encontram presentes nas cascas de frutas. Assim, o teor de vitamina $C$ analisado em frutas frescas geralmente é bem maior do que a quantidade encontrada em polpas já congeladas (GONÇALVES, 2008).

Segundo alguns autores, o araçá-boi é um fruto com potencial favorável em relação à economia, devido as condições de cultivo e manutenção de baixo custo, como por exemplo, não necessitam de defensivos agrícolas ou até mesmo valores aquisitivos altos para produzi-los. Este fruto apresenta fácil aceitação ao paladar dos consumidores (ANDRADE et al., 2012). Ainda pode auxiliar a evitar os radicais livres de modo que o organismo seja fortalecido contra algumas infecções e gripes (FRANZON et al., 2009).

Portanto, o presente trabalho teve como objetivo avaliar os parâmetros físico-químicos (umidade, acidez em ácido cítrico, $\mathrm{pH}$, cinzas, sólidos solúveis totais e lipídios), da casca, polpa e semente do fruto araçá-boi proveniente de três cidades da mesorregião do sudoeste do estado de Mato Grosso (Rio Branco, São José dos Quatro Marcos e Salto do Céu). 


\section{MATERIAIS E MÉTODOS}

\subsection{Obtenção, seleção e preparo da matéria-prima}

Os frutos de araçá-boi foram obtidos em duas coletas (a primeira coleta ocorreu no mês de setembro de 2015 e a segunda no mês de junho de 2016), nos municípios de Rio Branco, São José de Quatro Marcos e Salto do Céu, localizados na mesorregião do sudoeste do estado de Mato Grosso. Os frutos foram transportados para o laboratório de química da Universidade do Estado de Mato Grosso, campus Deputado Estadual Renê Barbour, localizado na cidade de Barra do Bugres, MT e mantidos sob refrigeração até início das análises.

Por ser um fruto não-climatério, a matéria-prima foi selecionada no estádio de maturação maduro, sem a presença de injúrias ou sinal de senescência. Logo após a seleção, os frutos foram lavados com sabão comercial, realizada a sanitização com hipoclorito de sódio $\left(5 \mathrm{mg} \mathrm{L}^{-1}\right)$ e secos com papel absorvente. Posteriormente, foi separado a casca, polpa e semente, sendo as partes acondicionadas em potes de polietileno e armazenadas a $-20{ }^{\circ} \mathrm{C}$ até realização das análises físico-químicas.

\subsection{Análise físico-química}

As análises físico-químicas de umidade (\%), cinzas (\%), pH, acidez em ácido cítrico (\%), sólidos solúveis totais ( ${ }^{\circ}$ Brix) e lipídios (\%) seguiram os procedimentos experimentais descritos pelo Instituto Adolfo Lutz (2008). Todas as análises foram realizadas em triplicata para minimizar os erros experimentais.

\subsection{Análise estatística}

$\mathrm{Na}$ análise estatística a comparação das médias foi realizada pela análise de variância (ANOVA) e teste de Tukey, com nível de significância a 5 \% (p < 0,05), utilizando o software Statistic 7.0.

\section{RESULTADOS E DISCUSSÃO}

\subsection{Avaliação físico-química da casca, polpa e semente de araçá-boi}

A Tabela 1 apresenta os resultados das análises físico-químicas de umidade, acidez em ácido cítrico, $\mathrm{pH}$ e cinzas de diferentes partes que compõem o fruto araçá-boi (casca, polpa e semente) proveniente de três cidades da mesorregião do sudoeste do estado de Mato Grosso (Rio Branco, São José dos Quatro Marcos e Salto do Céu). 
Tabela 1- Valores de umidade, acidez em ácido cítrico, $\mathrm{pH}$ e cinzas das diferentes partes que compõem o fruto araçá-boi (casca, polpa e semente), coletado nas cidades localizadas na mesorregião do sudoeste do estado de Mato Grosso (Rio Branco, Salto do Céu e Quatro Marcos).

\begin{tabular}{|c|c|c|c|c|c|c|c|}
\hline \multirow{2}{*}{ Parâmetros } & \multirow{2}{*}{$\begin{array}{c}\text { Parte da } \\
\text { fruta }\end{array}$} & \multicolumn{3}{|c|}{ Primeira coleta } & \multicolumn{3}{|c|}{ Segunda coleta } \\
\hline & & Rio Branco & Salto do Céu & Quatro Marcos & Rio Branco & Salto do Céu & Quatro Marcos \\
\hline \multirow{3}{*}{$\begin{array}{l}\text { Umidade } \\
(\%)\end{array}$} & Casca & $88,45 \pm 0,60^{\mathrm{aA} 1}$ & $88,62 \pm 0,21^{\mathrm{aA} 1}$ & $90,24 \pm 0,10^{\mathrm{aB} 1}$ & $88,54 \pm 0,13^{\mathrm{aA} 1}$ & $90,82 \pm 0,17^{\mathrm{aB} 2}$ & $90,82 \pm 0,28^{\mathrm{aB} 1}$ \\
\hline & Polpa & $94,42 \pm 0,11^{\mathrm{bA} 1}$ & $93,47 \pm 0,14^{\mathrm{bB} 1}$ & $90,87 \pm 0,11^{\mathrm{bC} 1}$ & $93,65 \pm 0,06^{\mathrm{bA} 2}$ & $94,56 \pm 0,13^{\mathrm{bB} 2}$ & $94,02 \pm 0,31^{\mathrm{bA} 2}$ \\
\hline & Semente & $54,95 \pm 0,14^{\mathrm{cA} 1}$ & $49,09 \pm 0,38^{\mathrm{cB} 1}$ & $48,71 \pm 0,08^{\mathrm{cB} 1}$ & $51,22 \pm 0,14^{\text {cA2 }}$ & $52,53 \pm 1,04^{\mathrm{cA} 2}$ & $48,43 \pm 0,30^{\mathrm{cB} 1}$ \\
\hline \multirow{3}{*}{$\begin{array}{c}\text { Acidez em } \\
\text { ácido cítrico } \\
(\%)\end{array}$} & Casca & $1,82 \pm 0,18^{\mathrm{aA} 1}$ & $1,82 \pm 0,01^{\mathrm{aA} 1}$ & $2,45 \pm 0,02^{\mathrm{a} 1}$ & $2,07 \pm 0,05^{\mathrm{aA} 2}$ & $2,46 \pm 0,02^{a \mathrm{~B} 2}$ & $2,48 \pm 0,01^{\mathrm{aB} 1}$ \\
\hline & Polpa & $1,83 \pm 0,02^{\mathrm{aA} 1}$ & $2,11 \pm 0,01^{\mathrm{bB} 1}$ & $2,77 \pm 0,01^{\mathrm{bC} 1}$ & $1,88 \pm 0,01^{\mathrm{bA} 2}$ & $2,10 \pm 0,01^{\mathrm{bB} 2}$ & $0,48 \pm 0,06^{\mathrm{bC} 2}$ \\
\hline & Semente & $1,75 \pm 0,03^{\mathrm{bA} 1}$ & $1,38 \pm 0,01^{\mathrm{cB} 1}$ & $1,01 \pm 0,01^{\mathrm{c} C 1}$ & $1,17 \pm 0,01^{\mathrm{c} A 2}$ & $2,13 \pm 0,01^{\mathrm{bB} 2}$ & $1,85 \pm 0,01^{\mathrm{cC} 2}$ \\
\hline \multirow{3}{*}{$\mathrm{pH}$} & Casca & $3,24 \pm 0,06^{\mathrm{aA} 1}$ & $3,27 \pm 0,07^{\mathrm{aA} 1}$ & $3,08 \pm 0,02^{\mathrm{aB} 1}$ & $3,05 \pm 0,01^{\mathrm{AA} 2}$ & $3,03 \pm 0,07^{\mathrm{aA} 2}$ & $3,04 \pm 0,01^{\mathrm{aA} 2}$ \\
\hline & Polpa & $3,10 \pm 0,01^{\mathrm{bA} 1}$ & $3,31 \pm 0,08^{\mathrm{aB} 1}$ & $2,79 \pm 0,06^{\mathrm{bC} 1}$ & $3,04 \pm 0,01^{\mathrm{aA} 2}$ & $3,02 \pm 0,05^{\mathrm{aA} 2}$ & $2,93 \pm 0,07^{\mathrm{b} A 2}$ \\
\hline & Semente & $3,74 \pm 0,01^{\mathrm{c} A 1}$ & $5,07 \pm 0,03^{\mathrm{bB} 1}$ & $5,05 \pm 0,03^{\mathrm{cB} 1}$ & $4,10 \pm 0,04^{\mathrm{bA} 2}$ & $3,38 \pm 0,08^{\mathrm{bB} 2}$ & $5,21 \pm 0,03^{c c 2}$ \\
\hline \multirow{3}{*}{$\begin{array}{c}\text { Cinzas } \\
(\%)\end{array}$} & Casca & $0,11 \pm 0,01^{\mathrm{aA} 1}$ & $0,08 \pm 0,01^{\mathrm{aA} 1}$ & $0,12 \pm 0,03^{\mathrm{aA} 1}$ & $0,34 \pm 0,03^{\mathrm{aA} 2}$ & $0,21 \pm 0,01^{\mathrm{aB} 2}$ & $0,38 \pm 0,02^{\mathrm{aA} 2}$ \\
\hline & Polpa & $0,24 \pm 0,02^{\mathrm{bA} 1}$ & $0,22 \pm 0,02^{\mathrm{bA} 1}$ & $0,24 \pm 0,02^{\mathrm{bA} 1}$ & $0,16 \pm 0,01^{\mathrm{bA} 2}$ & $0,25 \pm 0,02^{\mathrm{abB} 1}$ & $0,32 \pm 0,02^{\mathrm{bC} 2}$ \\
\hline & Semente & $0,61 \pm 0,04^{\mathrm{cA} 1}$ & $0,70 \pm 0,03^{\mathrm{cB} 1}$ & $0,67 \pm 0,02^{\text {сAB1 }}$ & $0,35 \pm 0,04^{\mathrm{aA} 2}$ & $0,29 \pm 0,02^{\mathrm{bB} 2}$ & $0,91 \pm 0,02^{\mathrm{cc} 2}$ \\
\hline
\end{tabular}

*Para cada um dos parâmetros físico-químicos, letras minúsculas iguais na mesma coluna, as médias não diferem entre si pelo teste de Tukey ao nível de probabilidade de $5 \%(p<0,05)$, entre as diferentes partes da fruta para uma mesma coleta e mesma cidade

**Para cada um dos parâmetros físico-químicos, letras maiúsculas iguais na mesma linha, as médias não diferem entre si pelo teste de Tukey ao nível de probabilidade de $5 \%(\mathrm{p}<0,05)$, para a mesma parte da fruta entre as diferentes localidades e mesma coleta

***Para cada um dos parâmetros físico-químicos, números iguais na mesma linha, as médias não diferem entre si pelo teste de Tukey ao nível de probabilidade de $5 \%(\mathrm{p}<0,05)$, para a mesma parte da fruta e mesma localidade, porém de coletas diferentes

Fonte: Próprio autor, 2018.

Os resultados apresentados na Tabela 1 mostraram que os maiores teores de umidade do fruto araçá-boi foram encontrados na polpa, seguido da casca e semente, independente do período ou local da coleta. Como o araçáboi é um fruto não-climatérico, ele precisa ser colhido em estádio maduro, e consequentemente, o maior teor de umidade nos frutos é na polpa, pois ocorre a transferência de umidade da casca para o interior, devido a troca osmótica com a casca no processo de amadurecimento (MATSUURA; FOLEGATTI, 2001).

Ao comparar as diferentes localidades e coletas, observa-se que a umidade apresenta pequenas variações. Na primeira coleta a umidade foi um pouco mais elevada para as amostras de São José de Quatro Marcos e na segunda coleta essas amostras não diferiram estatisticamente das coletadas em Salto do Céu, sendo ambas superiores a umidade apresentada pelas amostras 
de Rio Branco. Para as polpas, as umidades apesar de próximas, foram estatisticamente diferentes para todos as localidades, na primeira coleta. Porém, na segunda coleta a umidade das polpas de Salto do Céu foi superior. Ao comparar a umidade da semente, esta apresentou variação significativa entre os municípios de Rio Branco e os demais, sendo obtido uma umidade de 54,95 $\%$ na primeira coleta realizada em setembro de 2015 (período de seca). Já na segunda coleta, realizada em junho de 2016 a umidade aumentou nas amostras do município de Salto do Ceú (de 49,09 para 52,53\%), manteve a mesma em São José de Quatro Marcos e diminuiu em Rio Branco (54,95 para 51,22 \%).

A acidez indica a qualidade nutricional e sensorial dos alimentos, assim como o $\mathrm{pH}$, uma vez que frutos com alto teor de acidez e $\mathrm{pH}$ muito baixo não são normalmente consumidos em sua forma in natura (SOARES, 2009). Em relação a acidez, com exceção da segunda coleta de São José de Quatro Marcos, a semente apresentou menor conteúdo de acidez. Estes resultados corroboram com os obtidos no $\mathrm{pH}$, uma vez que independentemente do local e da época da coleta, a semente apresentou os maiores valores de $\mathrm{pH}$.

Ao comparar com a literatura, a acidez do araçá-boi coletado na região centro-oeste na mesorregião do sudoeste do estado de Mato Grosso em relação ao descrito por Canuto et al. (2010) para os frutos colhidos na Amazônia (1,8 $\%$, pode se verificar que os valores corroboram com os resultados obtidos em Rio Branco e Salto do Céu na primeira coleta, apresentando 1,86 e 1,82\%, respectivamente. Viana et al. (2012) encontraram valores de 2,88 \% para acidez da polpa de araçá-boi, enquanto Souza et al. (2007) encontraram valores de 3,93 $\%$, superiores aos encontrados nesse estudo.

Essa variação da acidez em relação as diferentes regiões no mesmo período (setembro de 2015) pode estar relacionada com a localidade dos araçazeiros, através das diferenças de manejo, poda, fertilidade do solo e irrigação nesse período. Já na coleta realizada no mês de junho, observou-se um aumento na acidez de todas as regiões, com aumento de até $10 \%$ nos valores. Nessa coleta, a maior acidez encontrada foi na casca, diferentemente da primeira coleta, onde a maior acidez foi encontrada na polpa. A acidez das sementes também foi superior a coleta anterior. Esse aumento pode estar relacionado a estação do ano que as coletas foram realizadas (primavera e inverno). $\mathrm{O}$ clima exerce grande influência principalmente em frutas cítricas, pois os frutos apresentam melhor desempenho em regiões com clima mais ameno, porém, essa limitação pode ser resolvida por meio de irrigação (AZEVÊDO, 2003). Portanto, a diferença pode estar relacionada ao tipo de manejo dos araçazeiros em cada região.

Corroborando com a acidez, o $\mathrm{pH}$ apresentou o mesmo perfil, sendo observado os menores valores para a casca e polpa e os maiores valores de $\mathrm{pH}$ para as sementes. De acordo com Soares (2009), existem fatores que influenciam no teor de acidez e $\mathrm{pH}$, como a época em que foi realizada a colheita, a quantidade de água presente no solo e o clima. Esses fatores podem estar 
associados com a diferença dos valores encontrados para as regiões analisadas e também com os valores descritos na literatura.

Segundo Araújo et al. (2006), o teor de cinzas é determinado para indicar a quantidade de matéria mineral contida nos alimentos. Embora os minerais não sejam considerados nutrientes, eles são compostos essenciais à manutenção das atividades do organismo humano. (GRANATO et al., 2009). Os valores do teor de resíduos por incineração (cinzas) encontrados no fruto do araçá-boi para a casca referentes as cidades de Rio Branco, Salto do Céu e São José dos Quatro Marcos foram de $0,11 \%, 0,08 \%$ e 0,12 \%, respectivamente. Esses resultados não corroboraram com a segunda coleta das três cidades, visto que, os resultados obtidos na primeira coleta foram inferiores aos encontrados na segunda coleta, sendo eles $0,34 \%, 0,21 \%$ e $0,38 \%$, respectivamente. Ao analisar a polpa do araçá-boi, Vanin (2015), verificou um valor de cinzas superior $(1,15 \%)$, ao encontrado nesse trabalho, diferença que pode estar relacionada aos tipos de cultivares.

Os sólidos solúveis contidos na polpa de frutos contêm compostos importantes que são fundamentais em proporcionar o sabor e consequentemente a aceitação dos consumidores. Além de apresentar correlação com teores de açúcares e ácidos orgânicos, propriedade importante para produtos que são comercializados in natura, devido a preferência dos consumidores por frutos doces (RESENDE et al., 2010).

O teor de sólidos solúveis ( ${ }^{\circ}$ Brix) na polpa do araçá-boi nas três cidades não apresentaram diferenças significativas, apenas a cidade de São José dos Quatro Marcos na segunda coleta que apresentou valor um pouco superior dos demais, com 6,13 ${ }^{\circ}$ Brix, enquanto o valor da primeira coleta em Rio Branco, Salto do Céu e Quatro Marcos foi de 5,13 ${ }^{\circ}$ Brix, $4,93^{\circ}$ Brix e 4,97 ${ }^{\circ}$ Brix, respectivamente e na segunda coleta de Rio Branco verificou-se $5,13^{\circ}$ Brix e em Salto do Céu $4,93^{\circ}$ Brix como pode se observar na Gráfico 1. 
Gráfico 1- Teor de sólidos solúveis totais ( ${ }^{\circ}$ Brix) da polpa de araçá-boi, coletado nas cidades localizadas na mesorregião do sudoeste do estado de Mato Grosso (Rio Branco, Salto do Céu e Quatro Marcos).

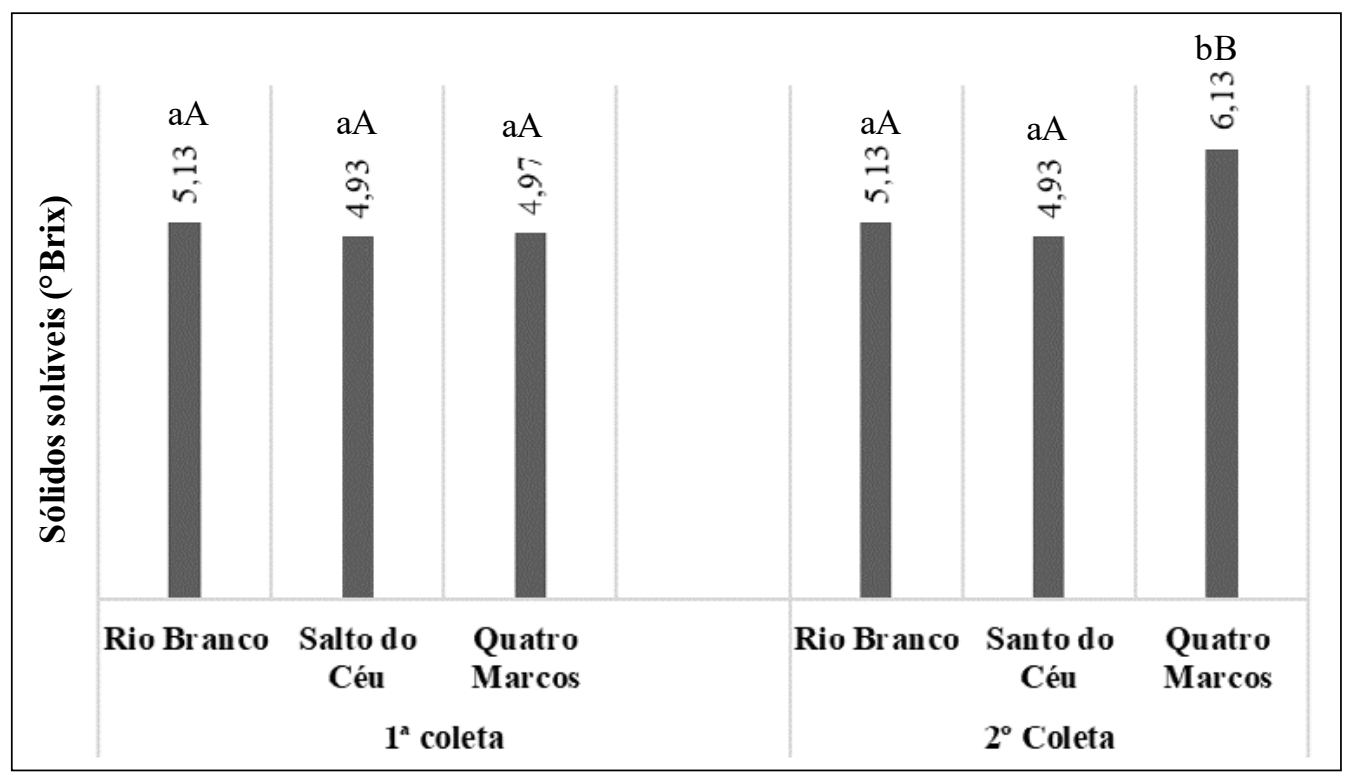

Letras minúsculas iguais, as médias não diferem entre si pelo teste de Tukey ao nível de probabilidade de 5\% ( $<<0,05)$, para uma mesma coleta, porém, entre as diferentes localidades. Letras maiúsculas iguais, as médias não diferem entre si pelo teste de Tukey ao nível de probabilidade de $5 \%(\mathrm{p}<0,05)$, para a mesma localidade, porém, em diferentes coletas.

Fonte: Próprio autor, 2018.

Viana (2012) encontrou valor de 4,56 ${ }^{\circ}$ Brix para polpa do araçá-boi, próximo ao encontrado nesse trabalho na primeira coleta e na segunda coleta em Rio Branco e Salto do Céu. Enquanto Soares (2009) verificou valor superior, apresentando 6,36 ${ }^{\circ}$ Brix, próximo ao encontrado em São José dos Quatro Marcos na segunda coleta. Comparando com a legislação vigente, os valores encontrados no fruto araçá-boi, são inferiores quando comparados aos padrões de identidade e qualidade de algumas frutas tropicais como acerola $\left(5,5^{\circ} \mathrm{Brix}\right)$, goiaba $\left(7,0^{\circ}\right.$ Brix $)$ e cajá $\left(9,0^{\circ}\right.$ Brix). O tipo de adubação, a época da colheita dos frutos e o estádio de maturação pode influenciar no teor de sólidos solúveis totais.

A fração lipídica encontrada na polpa do fruto araçá-boi foi baixa, pois a polpa do araçá-boi apresentou valores semelhantes na cidade de Salto do Céu e São José dos Quatro Marcos (2,13\% e 2,17\%), respectivamente, enquanto Rio Branco apresentou valor inferior, 1,26 \% (Gráfico 2). 
Gráfico 2- Teor de lipídios (\%) das diferentes partes que compõem o fruto araçáboi (casca, polpa e semente), coletado nas cidades localizadas na mesorregião do sudoeste do estado de Mato Grosso (Rio Branco, Salto do Céu e Quatro Marcos).

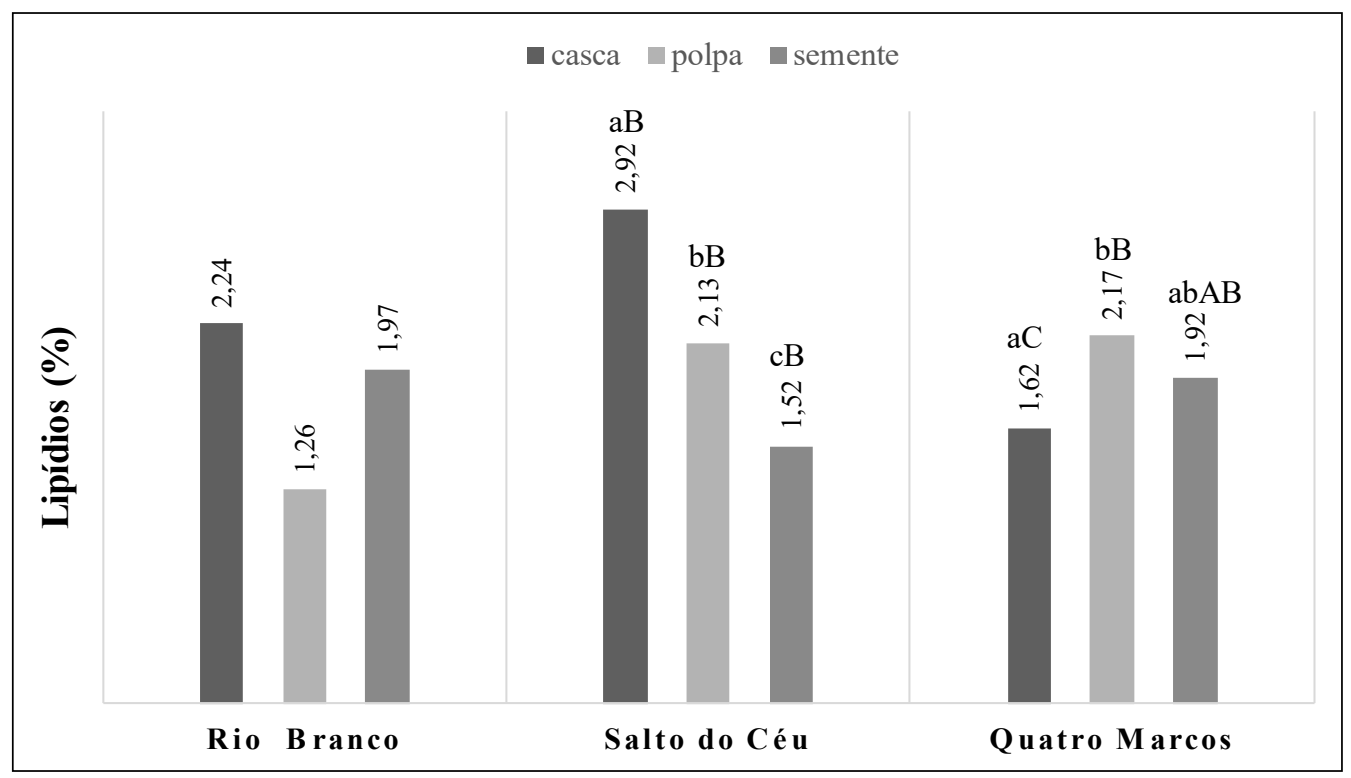

Letras minúsculas iguais, as médias não diferem entre si pelo teste de Tukey ao nível de probabilidade de $5 \%(\mathrm{p}<0,05)$, entre as diferentes partes da fruta para a mesma localidade Letras maiúsculas iguais, as médias não diferem entre si pelo teste de Tukey ao nível de probabilidade de $5 \%(\mathrm{p}<0,05)$, para a mesma parte da fruta, porém, em diferentes localidades Fonte: Próprio autor, 2018.

O valor obtido na casca foi de $2,24 \%$, valor superior ao encontrado na casca, em Salto do Céu o valor obtido na casca também foi superior ao da polpa com 2,92\%, enquanto em São José dos Quatro Marcos o valor encontrado na casca foi de 1,92\%, valor inferior ao da polpa. Os valores da massa lipídica das sementes corroboraram nas cidades de Salto do Céu e São José dos Quatro Marcos, com 2,13\% e 2,17\%, respectivamente, valor superior do encontrado em Rio Branco com $1,26 \%$.

Os resultados obtidos nesse presente trabalho foram maiores do que os apresentados na literatura. Nos estudos realizados pelo Ministério da Saúde (2002), foi encontrado teor de lipídios de $0,60 \%$ na polpa do araçá-boi. A análise de lipídios não foi realizada em duas coletas como as demais analises físicoquímicas por falta de matéria-prima da primeira coleta.

Os lipídios assim como as proteínas e os carboidratos são macronutrientes essenciais para o organismo, pois fornecem energia ao corpo e auxiliam outros processos celulares vitais. Além disso os lipídios desempenham o papel de transportadores de vitaminas lipossolúveis, nutrientes e também de algumas 
substâncias que apresentam solubilidade em gorduras, como as vitaminas A, D, E, K, junto com proteínas que desenvolvem a estrutura principal das membranas celulares (PITA, 2012).

\section{CONCLUSÃO}

Diante dos resultados obtidos conclui-se que o araçá-boi é um fruto ácido, com baixo teor de lipídios e cinzas, porém, com elevado conteúdo de água. De maneira geral, a casca e polpa apresentam características físicoquímicas semelhantes e diferentes da semente. Além disso, o período e região da coleta influenciaram em todas as características físico-químicas do fruto.

\section{AGRADECIMENTOS}

Os autores agradecem à Universidade do Estado de Mato Grosso, pelo suporte estrutural e as agências de fomento à pesquisa pelo apoio financeiro, Fundação de Amparo à Pesquisa do Estado de Mato Grosso (processo $\mathrm{n}^{\circ}$ 0575980/2018), Conselho Nacional de Desenvolvimento Científico e Tecnológico pela bolsa de pesquisa DCR (processo n³13859/2017-5).

\section{REFERÊNCIAS}

ANDRADE, D. R. M et al. Avaliação da composição química do araçá em duas localidades do sul do Brasil. Anais, XXII Congresso Brasileiro de Fruticultura. Bento Gonçalves, 2012.

ARAÚJO, Adriano A. de S. et al. Determinação dos teores de umidade e cinzas de amostras comerciais de guaraná utilizando métodos convencionais e análise térmica. Revista Brasileira de Ciências Farmacêuticas, v. 42, n. 2, p. 269- 277, 2006.

AZEVÊDO, Cláudio Luiz L. Sistema de Produção de Citros para o Nordeste. Cruz das Almas: Embrapa Mandioca e Fruticultura, 2003.

CANUTO, Gisele A. B. et al. Caracterização físico-química de polpas de frutos da Amazônia e sua correlação com a atividade anti-radical livre. Revista Brasileira de Fruticultura, v. 32, n. 4, p. 1196-1205, 2010.

FALCÃO, Martha de A. et al. Fenologia e produtividade do araçá-boi (Eugenia stipitata, Myrtaceae) na Amazônia central. Acta Amazônica, v. 30, n. 1, p. 9-21, 2000.

FERREIRA, Maria das Graças R.; RIBEIRO, George D. Coleção de fruteiras tropicais da Embrapa Rondônia. Rondônia: Embrapa Rondônia, 2006.

FRANZON, Rodrigo Cezar et al. Araçás do gênero Psidum: principais espécies, ocorrência, descrição e uso. Planaltina: Embrapa Cerrados, 2009. 
GENTIL, Daniel Felipe de O; FERREIRA, Sidney Alberto do N. Métodos de extração \& limpeza de sementes de araçá-boi (Eugenia stipitata). Acta Amazônica, v. 30, n. 1, p. 23- 30, 2000.

GONÇALVES, Any Elisa de S. S. Avaliação da capacidade antioxidante de frutas e polpas de frutas nativas e determinação dos teores de flavonóides e vitamina $C$. 2008. 88 f. Dissertação (Mestrado em Ciência dos Alimentos) - Universidade de São Paulo, São Paulo, 2008.

GRANATO, Daniel; PIEKARSKI, Flávia V. B. W. P.; RIBANI, Rosemary H.

Composição mineral de biscoitos elaborados a partir de farinhas de amêndoa ou amendoim adicionadas de ferro. Pesquisa Agropecuária Tropical, v. 39, n. 2, p. 92-97, 2009.

INSTITUTO ADOLFO LUTZ. Métodos Físico-Químicos para Análise de Alimentos. 4 ed. São Paulo: Instituto Adolfo Lutz, 2008.

MATSUURA, Fernando César A. U.; FOLEGATTI, Marília Ieda da S. Banana: póscolheita. Brasília: Embrapa Informação Tecnológica, 2001.

NERI-NUMA, Iramaia Angélica et al. Evaluation of the antioxidant, antiproliferative and antimutagenic potential of araçá-boi fruit (Eugenia stipitata Mc Vaugh- Myrtaceae) of the Brazilian Amazon Forest. Food Research International, v. 50, n. 1, p. 70-76, 2013.

PITA, Julyane da S. L. Caracterização físico-química e nutricional as polpa e farinha da casca de maracujazeiros do mato e amarelo. 2012. 80 f. Dissertação (Mestrado em Engenharia de Alimentos) - Universidade Estadual do Sudoeste da Bahia, Itapetinga, 2012.

RESENDE, Juliano T. V. de et al. Produtividade e teor de sólidos solúveis de frutos de cultivares de morangueiro em ambiente protegido. Horticultura Brasileira, v. 28, n. 2, p. 185-189, 2010.

SACRAMENTO, Célio K.; BARRETO, Waldemar de S.; FARIA, José C. Araçá boi: uma alternativa para agroindústria. Revista Bahia Agrícola, v. 8, n. 2, 2008.

SOARES, Eliza S. Caracterização de aditivos para secagem de araça-boi (Eugenia stipitata Mc Vaugh) em leito de espuma. 2009. 89 f. Dissertação (Mestrado em Engenharia de Alimentos) - Universidade Estadual do Sudoeste da Bahia, Itapetinga, 2009.

SOUZA, Patrick G. de et al. Bebida Láctea fermentada sabor de araçá-boi (Eugenia stipitata McVaugh) com diferentes concentrações de mel de abelha. Anais, XVI Jornada de Iniciação Científica PIBIC CNPq/FAPEAM/INPA, Manaus, 2007.

VANIN, Camila R. Araçá amarelo: atividade antioxidante, composição nutricional e aplicação em barra de cereais. 2015. 117 f. Dissertação (Mestrado Profissional em 
Tecnologia de Alimentos) - Universidade Tecnológica Federal do Paraná, Londrina, 2015.

VIANA, Eliseth de S. et al. Caracterização físico-química e sensorial de geleia de mamão com araçá-boi. Revista Brasileira de Fruticultura, v. 34, n. 4, p. 1154-1164, 2012. 